Arq. Bras. Med. Vet. Zootec., v.66, n.2, p.439-444, 2014

\title{
Citoinclusão de capa leucocitária e medula óssea de cães: padronização da técnica
}

\author{
[Cell block of canine buffy coat and bone marrow in paraffin blocks: technique standardization]
}

\author{
M.B. Paiva, G.M. Gouveia, H. Fioravanti, M.C.R. Luvizotto
}

Faculdade de Medicina Veterinária -Unesp - Araçatuba, SP

\begin{abstract}
RESUMO
A técnica de citoinclusão é amplamente utilizada e reconhecida por profissionais da área da saúde, em particular médicos patologistas, porém as informações sobre a aplicação desse método em medicina veterinária ainda são raras. Análises citológicas de medula óssea e da capa leucocitária (porção do sangue formada por concentrados de leucócitos) são amplamente utilizadas no diagnóstico de patologias de origem neoplásica e não neoplásica e de agentes infecciosos. Embora a importância do uso da técnica seja amplamente reconhecida, não há registro da utilização de amostras citológicas de medula óssea e capa leucocitária na confecção de citoinclusões em blocos de parafina, como meio de diagnóstico no segmento médico veterinário. Assim, este trabalho tem como objetivo elaborar um protocolo de citoinclusão em parafina para amostras citológicas de medula óssea e capa leucocitária de cães. Foram submetidas à técnica de citoinclusão 110 amostras de capa leucocitária e 44 de medula óssea de cães portadores ou não de enfermidade sistêmica, sendo que em $68 \%$ destas, tanto para a capa leucocitária quanto para a medula óssea, as amostras se mostraram viáveis. A utilização do álcool $95 \%$ como fixador e de etapas no processamento histológico de 20 minutos (álcool absoluto, xilol e parafina, três banhos cada) foi crucial para a qualidade dos cortes histológicos e para a análise microscópica dos espécimes corados pela hematoxilina-eosina. A separação mecânica da capa leucocitária e a centrifugação do aspirado de medula óssea foram eficientes e de baixo custo no preparo das citoinclusões. Ressalta-se a importância na padronização da técnica de citoinclusão, em particular para amostras de capa leucocitária e medula óssea, visando à obtenção de espécimes de qualidade independentemente das limitações de equipamentos.
\end{abstract}

Palavras-chave: cão, citoinclusão, capa leucocitária, medula óssea, técnica

\begin{abstract}
The cell block technique is widely used and recognized by health professionals, but lacks in information regarding the specific contribution of this method to veterinary medicine. The cytology of bone marrow and buffy coat (cellular portion of the hole blood) are widely used in the diagnosis of neoplastic and nonneoplastic diseases, and also for the detection of infectious agents. Although the importance of these samples is widely recognized, there is no information about the use of buffy coat and bone marrow samples in the cell block procedure among the research material used for this paper. This work aims for the cell block standardization for canine buffy coat and bone marrow samples. We collected 110 buffy coat samples and 44 bone marrow samples for the cell block preparation, and $68.2 \%$ of buffy coat and bone marrow proved to be viable at the end of the procedure. The 95\% ethanol fixatives along with the 20 minute processing steps (absolute ethanol, xilol and paraffin, 3 of each) were crucial for the quality of the material both in microtomy and optical microscopy. Mechanical separation of the buffy coat proved to be easy and cheap and was used to compose the cell block technique. In this research we emphasized the importance of cell block standardization in order to develop and easy, inexpensive and reproducible method, regardless of any of the professionals' limitations.
\end{abstract}

Keywords: dog, cell block, buffy coat, bone marrow, technique

Recebido em 30 de agosto de 2012

Aceito em 5 de setembro de 2013

E-mail: millabpaiva@yahoo.com.br 


\section{INTRODUÇÃO}

A citoinclusão compreende $\mathrm{o}$ ato de inserir amostras citológicas em blocos de parafina, com a finalidade de auxiliar na qualidade do diagnóstico citológico e também de se obter espécimes de reserva para serem utilizados nas técnicas diagnósticas complementares, como a imuno-histoquímica e imunocitoquímica (Keyhani-Rafagas et al., 1984; Bales e Durfee, 1992; Mayall et al.,1997; Liu et al.,1998; Ardengh et al. 2008; Varsegi e Shigham, 2009).

Em virtude da grande variabilidade de técnicas testadas e utilizadas na confecção de cito inclusões, a comparação entre elas torna-se inviável, gerando grandes dificuldades na padronização de um método universal para essa modalidade de processamento e armazenamento de material destinado ao exame citológico (Nathan et al., 2000; Nigro et al., 2007; Shivakumarswamy et al., 2012).

O desenvolvimento e a padronização da técnica de citoinclusão devem atender aos seguintes requisitos: manutenção da morfologia celular e arquitetura tecidual; otimização do tempo de processamento das amostras sem perda de qualidade do material; obtenção de material de reserva suficiente para a realização de testes como colorações especiais e reações de imunohistoquímica; e, por fim, desenvolvimento de método simples, de custo reduzido e reprodutível (Burt et al., 1986; Nathan et al., 2000; Kulkarni et al., 2008).

Um dos pontos mais importantes da técnica reside na possibilidade de perda do material durante o processamento. Adaptações e modificações na técnica foram aplicadas, como o uso de ágar ou plasma/tromboplastina para agregação do sedimento celular, porém esses métodos também possuem desvantagens e, em determinadas situações, não são recomendados (Kung et al., 1989).

Visando à maximização da utilidade das citoinclusões, as técnicas de fixação e processamento de amostras devem ser modificadas para que haja um aumento na sensibilidade dos diagnósticos citológicos e maior qualidade nas técnicas complementares, como a imuno-histoquímica (Krogerous e Andersson, 1988; Kung et al., 1989; Gangane et al., 2007).
Análises citológicas de medula óssea e da capa leucocitária (porção do sangue constituída por concentrados de leucócitos) são amplamente utilizadas no diagnóstico de patologias de origem neoplásica e não neoplásica e de agentes infecciosos (Chandra e Chandra, 2011). Embora a importância da utilização das amostras seja amplamente reconhecida, não existe registro da utilização de amostras de medula óssea e capa leucocitária na confecção de citoinclusão em blocos de parafina entre o acervo utilizado para esta pesquisa.

Este trabalho tem como objetivo a padronização da técnica de citoinclusão, incluindo os processos de fixação, desidratação, diafanização e inclusão em parafina para amostras citológicas de medula óssea e capa leucocitária de cães portadores ou não de enfermidade sistêmica.

\section{MATERIAL E MÉTODOS}

Foram utilizadas 110 amostras de sangue periférico e 44 de medula óssea de cães para a confecção das citoinclusões, todas coletadas com o consentimento prévio dos proprietários e de acordo com os Princípios Éticos de Experimentação Animal - COBEA, com aprovação da Comissão de Ética na Experimentação Animal - CEEA, sob número 006754-2009. O sangue periférico (aproximadamente $3 \mathrm{~mL}$ ) foi coletado por venopunção da cefálica em cães de médio e grande porte e da veia jugular em animais de pequeno porte e filhotes. Para o procedimento, foram utilizadas seringas de 5 ou $10 \mathrm{~mL}$, agulhas de $22 \mathrm{G}$ e $29 \mathrm{G}$ e tubos contendo anticoagulante (EDTA).

Para a medula óssea, a coleta foi no esterno, realizando-se previamente um botão anestésico com cloridrato de lidocaína a $2 \%$, com o auxílio de agulhas de Rosenthal em animais de médio e grande porte, e agulhas $40 \mathrm{~mm} \times 12 \mathrm{~mm}$ em animais de pequeno porte e filhotes e seringa de $20 \mathrm{~mL}$. Foi estipulado o volume máximo de $1 \mathrm{~mL}$ de material aspirado e consequente inutilização de aspirados com grandes volumes, que inviabilizariam a execução da técnica por conterem percentual maior de hemácias e, portanto, menor percentual de células representativas do tecido pesquisado. 
Para a obtenção da capa leucocitária do sangue periférico, as amostras foram centrifugadas (centrífuga Excelsa da FANEM $^{\circledR}$, modelo 206BL) a 2000rpm por cinco minutos. Após a retirada do plasma com o auxílio de uma pipeta Pasteur, a capa leucocitária foi removida do tubo com o auxílio de uma pipeta de 10 microlitros e inserida em tubos de $1,5 \mathrm{~mL}$ contendo álcool a $95 \%$, sendo novamente centrifugada na mesma velocidade e tempo para a formação do agregado celular, ou pellet, e troca do fixador.

Os espécimes de medula óssea foram também submetidos à fixação com álcool a $95 \%$, porém o fixador foi aspirado diretamente na seringa utilizada para coleta, com o objetivo de preservação máxima da viabilidade das células obtidas no procedimento.

Após 24 a 48 horas de fixação, os agregados celulares foram retirados dos tubos, clivados longitudinalmente e inseridos em cassetes histológicos, que foram submetidos a banhos crescentes de álcool, seguindo para os banhos de xilol e parafina, todos com duração máxima de 20 minutos. Nas amostras escassas de medula óssea, foi necessário o uso de esponjas histológicas nos cassetes, evitando a perda de material. As amostras foram incluídas em parafina (Fig. 1a e 1b) e realizaram-se cortes de 4 micrômetros, os quais foram corados em hematoxilina e eosina (HE).

As lâminas foram examinadas em microscópio óptico nas objetivas de quatro, 10 e 40 vezes. A identificação de quantidade suficiente de células com morfologia preservada foi o critério utilizado para a amostra ser considerada viável (Fig. 1c, 1d, 1e e 1f).

Para o emprego da técnica acima descrita, foram feitos testes pilotos a fim de se eleger o melhor fixador, o tempo de centrifugação e o tempo de processamento dos espécimes. Para tanto, foi utilizado como fixador o formol a $10 \%$, álcool a $70 \%$ e álcool absoluto; também foram testados os tempos de uma hora, 40 minutos e 30 minutos nos processos de desidratação e diafanização aplicados no processamento de rotina em histopatologia.

\section{RESULTADOS E DISCUSSÃO}

A padronização do tempo de fixação (24 a 48 horas) representa o primeiro ajuste na técnica responsável pela qualidade do material, já que amostras fixadas com tempo superior a 48 horas se mostraram endurecidas e ressecadas.

A análise do teste piloto aplicada aos diferentes fixadores mostrou que o uso do formol a $10 \%$ resultou em preservação da morfologia celular, porém o tempo do processamento foi maior devido à utilização do álcool amoniacal para a retirada de pigmento de formol, frequentemente observado nas amostras. A fixação pelo álcool $70 \%$ não propiciou a formação do agregado celular suficientemente consistente, fazendo-se necessário o uso do papel de seda para que as amostras permanecessem nos cassetes até o final do processamento, o que gerou frequente perda do material ou quantidade insuficiente para inclusão em parafina e, consequentemente, redução na acurácia do exame.

Já a fixação pelo álcool absoluto provocou acentuada desidratação das amostras, acarretando em dificuldade na inclusão em parafina, decorrente da dureza das amostras, e, assim, inviabilizou a etapa de microtomia. A fixação pelo álcool a 95\% mostrou ser adequada à formação dos agregados celulares destinados aos passos subsequentes da rotina de inclusão em parafina, microtomia e coloração de rotina (Fig. 1).

Quanto aos tempos aplicados à desidratação e diafanização das amostras, de uma hora, 40 e 30 minutos, estes promoveram o endurecimento acentuado, tanto com o ressecamento quanto com o excesso de diafanização e impregnação pela parafina, o que também inviabilizou a etapa de microtomia. Os três banhos de álcool absoluto, três de xilol e três de parafina, todos com duração de, no máximo, 20 minutos, foram suficientes para a obtenção de espécimes de excelente qualidade, particularmente quanto à inclusão em parafina e microtomia.

Das 110 amostras da capa leucocitária de cães submetidos ao protocolo foi possível realizar a técnica com êxito em 75 amostras, ou seja, 68,0\% de viabilidade (Fig. 1a,1c e 1e). Nas demais 25 amostras, nas quais o processo de inclusão não foi viável, o material citológico recuperado foi insuficiente para formar um agregado constituído de celularidade representativa. 


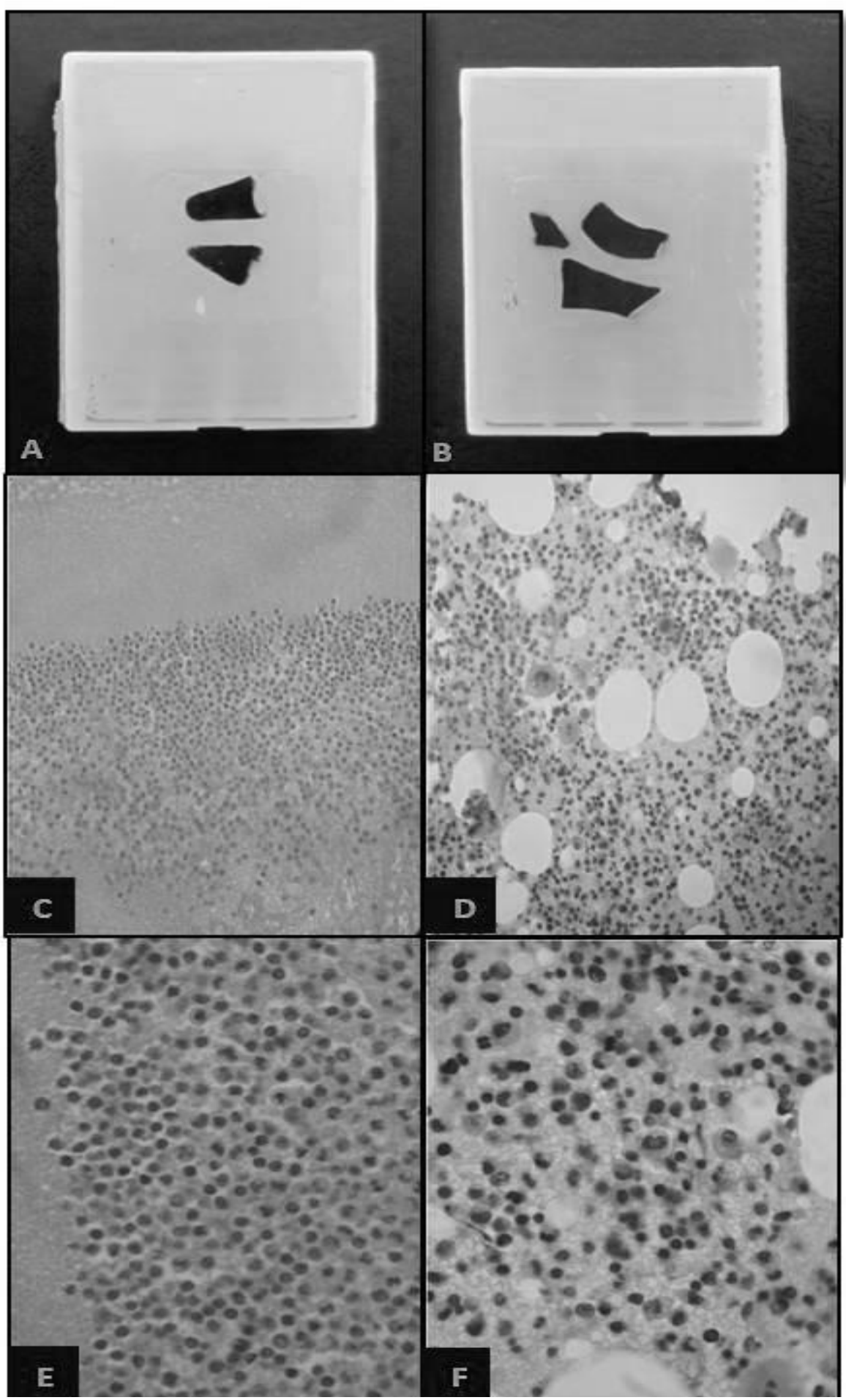

Figura 1. Ilustração de amostras de capa leucocitária e medula óssea. Aspecto das citoinclusões de capa leucocitária (A) e medula óssea (B) à macroscopia. População celular rica em leucócitos junto a hemácias em espécime de capa leucocitária (C e E),HE, objetiva de 10 e 40x, respectivamente. População mista de células na medula óssea entremeadas por gotículas de gordura (D e F),HE objetiva de 10 e 40x, respectivamente. 
As amostras da punção de medula óssea $(n=44)$ também revelaram viabilidade e preservação de material de reserva em $68 \%$ (Figura 1b), exibindo à microscopia óptica quantidade e qualidade na preservação da morfologia celular (Fig. 1d e 1f).

Em ambos os casos, a escassez de material coletado foi em decorrência das dificuldades na coleta, ou mesmo por se tratar de animais de pequeno porte, nos quais o processo mecânico de formação do pellet mostrou-se inadequado, ocasionando perda durante os procedimentos subsequentes.

Vários fixadores são utilizados em técnicas de citoinclusão, como formalina tamponada, solução de Bouin, ácido pícrico, fixador Carnoy, fixador B-5 mercúrio e etanol. Essa variedade está diretamente relacionada à diversidade de técnicas existentes, adaptadas à necessidade e especificidade de cada pesquisador (Domagala et al., 1990; Bales e Durfee, 1992; Gurley et al., 1992; Zito et al., 1995)

O tempo de processamento de amostras citológicas destinadas a citoinclusões geralmente é idêntico ao processamento histológico de rotina (Nigro et al., 2007; Kulkarni et al., 2008; Engohan-Aloghe et al., 2010; Shivakurmarswamy et al., 2012), com poucas variações, a fim de acelerar o processo, como o uso de reagentes aquecidos nos banhos histológicos (Gangane et al., 2007). Devido à grande quantidade de hemácias no material utilizado neste estudo, fez-se necessária a adaptação do processo de cito- inclusão a fim de evitar o ressecamento e endurecimento, mais frequente em amostras que contêm quantidades apreciáveis de hemácias, como as utilizadas neste experimento.

A recuperação de leucócitos do sangue periférico pode ser obtida por métodos que utilizam a separação mecânica e a de gradiente de densidade com o emprego do Ficoll® (Miltenyi Biotec, 2011; Sengar, 1968). Neste estudo foi escolhido o método de separação mecânica por se tratar de baixo custo, não necessitando de equipamento específico. A quantidade de leucócitos em meio a hemácias observados na análise microscópica foi adequada para o estabelecimento de critérios de diagnóstico.
Uma das principais dificuldades reside na manutenção de quantidade significativa do espécime após o processamento. Muito embora existam referências de pesquisas relacionadas ao uso das citoinclusões com finalidade diagnóstica, poucas são aquelas que fornecem detalhes sobre a metodologia empregada (Kulkarni et al., 2008).

\section{CONCLUSÃO}

Neste trabalho, foi ressaltada a importância da padronização da técnica de citoinclusão especificamente para amostras de capa leucocitária e medula óssea, visando à obtenção de método fácil, de baixo custo e reprodutível, com vistas à obtenção de um diagnóstico complementar. A técnica de citoinclusão apresentada foi bem-sucedida em pesquisa imuno-histoquímica utilizando o sangue periférico e a medula óssea em animais vivos, vista como uma vantagem representativa para a observação temporal ante-mortem dos animais quando submetidos a estímulos diversos, como curso de doenças, senilidade, resposta imune de animais resistentes a enfermidades endêmicas, entre tantos outros.

\section{REFERÊNCIAS}

ARDENGH, J.C.; LOPES, C.V.; LIMA, F.P. et al. Cell block technique and cytological smears for the differential diagnosis of pancreatic neoplasms after endosonography-guided fineneedle aspiration. Acta Gastroenterol. Latinoamer., v.38, p.246-251, 2008.

BALES, C.E.; DURFEE, G.R. Cytological technique, part 1. In: KOSS L.G. Diagnostic Cytology and its Histopathologic Bases. 4.ed. Philadelphia, PA: Lippincott, 1992. p.1451-1474.

BURT, A.D.; SMILLIE, D.; COWAN, M.D.; ADAMS, F.G. Fine needle aspiration cytology: Experience with a cell block technique. J. Clin. Pathol., v.39, p.114-115, 1986.

CHANDRA, S.; CHANDRA, H. Comparision of bone marrow aspirate cytology, touch imprint cytology and trephine biopsy for bone marrow evaluation. Hematol. Reports, v.3, p.65-68, 2011.

DOMAGALA, W.M.; MARKIEWSKI, M.; TUZIAK, T. et al. Immunocytochemistry on fine needle aspirates in paraffin miniblocks. Acta Cytolog., v.34, p.291-296, 1990. 
ENGOHAN-ALOGHE， C.; HOTTAT, N.; NOËL, J.C. Accuracy of lymph nodes cell block preparation according to ultrasound features in preoperative staging of breast cancer. Diagn. Cytopathol., v.38, p.5-8, 2010.

GANGANE, N.; MUKERJI, M.S.; ANSHU; SHARMA, S.M. Utility of microwave processed cell blocks as a complement to cervico-vaginal smears. Diagnostic Cytopathol., v.35, p.338-341, 2007.

GURLEY, A.M.; SILVERMAN, J.F.; LASSALETTA, M.M. et al. The utility of ancillary studies in pediatric FNA cytology. Diagnostic Cytopathol., v.8, p.137-146, 1992.

KEYHANI-RAFAGAS, S.; O'TOOLE, R.V.; LEMING, M.F. Role of cell block in fine needle aspiration cytology. Acta Cytolog., v.28, p.630$631,1984$.

KROGERUS, L.A.; ANDERSSON L.C. A simple method for the preparation of paraffin embedded cell blocks from fine needle aspirates, effusions and brushings. Acta Cytolog., v.32, p.585-587, 1988.

KULKARNI, M.B.; DESAI, S.B; AJIT, D.; CHINOY, R.F. Utility of the thromboplastinplasma cell-block technique for fine-needle aspiration and serous effusions. Diagnostic Cytopathol., v.37, p.85-90, 2008.

KUNG, I.T.; YUEN, R.W.; CHAN, J.K. Technical notes: Optimal formalin fixation and processing schedule of cell blocks from fine needle aspirates. Pathol., v.21, p.143-145, 1989.

LIU, K.; DODGE, R.; GLASGOW, B.J.; LAYFIELD, L.J. Fine-needle aspiration: comparison of smear, cytospin, and cellblock preparations in diagnostic and cost effectiveness. Diagnostic Cytopathol., v.19, p.70-74, 1998.

MAYALL, F.; CHANG, B.; DARLINGTON, A. A review of 50 consecutive cytology cell block preparations in a large general hospital. J. Clin. Pathol., v.50, p.985-990, 1997.
MILTENYI BIOTEC. Manual: Isolation of mononuclear cells from human peripheral blood by density gradient centrifugation. Disponível em https://www.miltenyibiotec.com/download/proto cols_sample_preparation_en/1396/SP_MC_PB_ density_gradient.pdf. Acessado em: 14 out 2011.

NATHAN, N.A.; NARAYAN, E.; SMITH, M.M.; HORN, M.J. Cell-block cytology. Improved preparation and its efficacy in diagnostic cytology. Am. J. Clin. Pathol., v.114, p.599-606, 2000.

NIGRO, K.; TYNSKI, Z.; WASMAN, J. et al. Comparision of cell block preparation methods for nongynecologic thinprep specimens. Diagnostic Cytopathol., v.3, p.640-643, 2007.

SENGAR, D.P.S.; JEROME, F.N.; DOUGLAS, R.J. A simple method for separation of buffy coat from peripheral blood of chickens. Canadian J. Comparat. Med., v.32, p.593-597, 1968.

SHIVAKUMARSWAMY, U.; ARAKERI, S.U.; KARIGOWDAR, H.; YELIKAR, B.R. Diagnostic utility of the cell block method versus the conventional smear study in pleural fluid cytology. J. Cytol., v.29, p.11-15, 2012.

VARSEGI,G.; SHIDHAM, V. Cell block preparation from cytology specimen with predominance of individually scattered cells. $J$. Visualized Experiments. Wisconsin, v.29, p.1-7, 2009.

ZITO, F.A.; GADALETA, C.D.; SALVATORE, C. et al. A modified cell block technique for fine needle aspiration cytology. Acta Cytolog., v.39, p.93-99, 1995. 